\title{
Breastfeeding and Complementary Feeding: Practice, Knowledge and Socioeconomic Profile of Mothers of Children up to 2 Years of Age at a Health School of Pará
}

Letícia Barbosa Barros ${ }^{1}$, Polliany Ribeiro de Quadros ${ }^{1}$, Karlla Lorenna dos Santos Anjos ${ }^{1}$, Natielle Rosendo Chaves ${ }^{1}$, Wanessa Costa da Silva ${ }^{1}$, Jean Carlos Alves de Lima Souza', Amanda Letícia Bezerra Campos', Marcela Bianca Lima Santos ${ }^{1}$, Thais Martins Novaes ${ }^{1}$, Nathasha Nunes Ribeiro', Bruna Vaz Pereira Rodrigues2, Amanda Cristina Alvino Feio $^{3}$, Erica Gomes do Nascimento Cavalcante ${ }^{2}$

\section{Abstract}

Objective: This study aims to evaluate socioeconomic profile, practice and knowledge of mothers of children up to 2 years old on breastfeeding and complementary feeding.

Methods: Interviews applied to 104 mothers who were subjected to research protocol consists of 33 questions on breastfeeding, complementary feeding, sociodemographic and obstetrical data.

Results: most mothers were between 20 and 34 years old, was in a stable union, had completed high school, was unemployed, was subjected to caesarean operation, and attended six or more prenatal consultations. Regarding breastfeeding and complementary feeding mothers had good knowledge of the subject and demonstrated practice properly on most issues.

Conclusion: Such observed data highlight the need for studies on the causes of differences between practice and knowledge about
1 Universidade do Estado do Pará. Belém-PA, Brazil.

2 Centro Universitário do Estado do Pará (CESUPA). Belém-PA, Brazil.

3 Universidade da Amazônia (UNAMA) Belém-PA, Brazil.

Contact information:

Karlla Lorenna dos Santos Anjos.

Address: Universidade do Estado do Pará. Trav. Perebebuí n 2623, CEP 66095-450, Belém-PA, Brazil.

Tel: +55 91 3299-2200

झ anjoskarlla@gmail.com 
breastfeeding and complementary feeding, analyzing the received prenatal and failures or absence of post-natal care in to clarify and assist the practical questions of mothers

\section{Keywords}

Complementary Feeding; Inappropriate Practices; Breastfeeding.

\section{Introduction}

Healthy infant feeding is fundamental to proper growth and development. After six months of age, breastfeeding should not be exclusive, other foods should be offered to the infant and it is recommended that breastfeeding be maintained until two years of age [1], emphasized by the World Health Organization (WHO) as important public health policies [2].

It is known that breastfeeding and the introduction of food are influenced by several factors, such as the mother, which is a reference for child care. The motivations that lead mothers to decide about breastfeeding may be linked to the culture, lifestyle, and influence of society. From the nutritional point of view, early introduction of food can be disadvantageous and, even when introduced at the right time, diet should have adequate amounts of macro and micronutrients (notably iron, zinc, calcium, vitamin $A$, vitamin $C$ and acid folic), free from contamination (biological, chemical or physical), easy to consume and accept, with acceptable cost and prepared from foods usually consumed by the family [3], requiring adequate preparation and administration.

Although there is a wide scientific knowledge about the importance of the practice of breastfeeding and correct complementary feeding, there are few studies that portray this aspect in the Brazilian North region and, more specifically, in the State of Pará. Studies on this subject are fundamental so that the knowledge produced can be reflected in an improvement in children's health indicators, contributing to the reduction of morbidity and mortality in this part of the population and preventing future consequences that poor nutrition may cause.

Considering the diverse implications that feeding has on child growth, development and health, the present study aims to analyse breastfeeding and complementary feeding of children up to 2 years of age attended at the School Health Center of the Pará State University, including a survey of the socioeconomic profile of mothers, in addition to their knowledge and practice on the subject.

\section{Methods}

This is a cross-sectional, observational and descriptive study conducted at the School Health Center of the Pará State University, through a research protocol applied to the mothers of children up to 2 (two) years old who were in waiting room for pediatric outpatient care and/or vaccination.

A total of 104 mothers were interviewed through a research protocol composed of 33 questions about breastfeeding, complementary feeding, socioeconomic profile and obstetric data. The questionnaires were identified by numbers and applied directly to the mothers of the children by the interviewers, in a reserved manner, in the unit itself, for a period of 5 consecutive months. It was not necessary to mention their names, in order to ensure the preservation of their identity. 
In spite of to compose the study population, mothers of children aged 0 to 2 (two) years who received care at the School Health Center of the Pará State University were adopted as inclusion criteria. Children who presented some type of basic pathology that interfered in the capacity of breastfeeding and/or the introduction of foods were excluded from our research; mothers who were unable to breastfeed, for disease or medical recommendation; and children whose mothers did not remember the information needed for the study. Also excluded were mothers who refused to participate in the study or to answer any of the questions contained in the questionnaire, as well as those who did not sign the Free and Informed Consent Form.

Data relevant to the survey were collected in a protocol, which was composed of questions about the mothers' knowledge about breastfeeding and infant feeding and about the food development of the child under study. In addition, it presented questions regarding the socioeconomic and obstetric data of the interviewees, such as education level and professional occupations, type of delivery and number of prenatal consultations.

All patients were studied according to the precepts of the Declaration of Helsinki and the Nuremberg Code, respecting the National Research Council's Human Research Standards (Rs. CNS 466/12) after approval by the Research Ethics Committee of the Pará State University (UEPA), authorized by the coordination of the medical course of the University, by the School Health Center of the Pará State University, by the research supervisor and by the interviewees, through the Informed Consent Form, which was signed by all the participants of the research.

The software Microsoft ${ }^{\circledR}$ Word 2007, Microsoft ${ }^{\circledR}$ Excel 2007, was used for creating tables and graphs. According to the type of the variables, descriptive statistical analysis was applied, being informed the percentage and absolute values of the data analyzed.

\section{Results}

A total of 104 mothers participated of the survey. Concerning the questions about their children, $62.5 \%$ of them were older than or equal to 6 months, $52.9 \%$ were first-born, and $66.7 \%$ had only one brother.

Regarding the demographic data of the mothers, it was noted that the majority (78.8\%) were in the age group between 20 and 34 years and $65.5 \%$ of them were in a stable union. Regarding the level of education, $40.4 \%$ had completed high school, $24 \%$ incomplete high school. In terms of situation in the job market, 65.4\% were unemployed. (Table 1)

Table 1. Demographic data of mother of children up to 2 years of age attended at the School Health Center of the Pará State University.

\begin{tabular}{|l|c|c|}
\hline \multicolumn{1}{|c|}{ Data } & N $=104$ & $\%$ \\
\hline Age & & \\
\hline$<20$ years & 13 & 12.5 \\
\hline 20 a 34 years & 82 & 78.8 \\
\hline >34 years & 9 & 8.7 \\
\hline Civil Status & & \\
\hline Single & 36 & 34.6 \\
\hline Stable union & 68 & 65.5 \\
\hline Educational Level & & \\
\hline Incomplete elementary school & 4 & 3.8 \\
\hline Complete elementary school & 14 & 13.5 \\
\hline Incomplete high school & 25 & 24.0 \\
\hline Complete high school & 42 & 40.4 \\
\hline Incomplete higher degree & 5 & 4.8 \\
\hline Complete higher degree & 14 & 13.5 \\
\hline Job Market Status & & \\
\hline Permanent job/Maternity leave & 36 & 14.4 \\
\hline Unemployed & 68 & 65.4 \\
\hline Type Of Delivery & & \\
\hline Normal childbirth & 39 & 37.5 \\
\hline Cesarean section & 65 & 62.5 \\
\hline Prenatal Consultation & & \\
\hline < 6 & & 14.4 \\
\hline Did not know & & 83.6 \\
\hline
\end{tabular}

Source: research protocol 
Most of mothers (62.5\%) underwent cesarean delivery and $83.6 \%$ were submitted to the complete prenatal care, with 6 or more medical visits.

With respect to breastfeeding practices, of the 39 children under 6 months of age, 92.3\% were breastfed, and of these, $72.2 \%$ received exclusive breastfeeding. Among the 65 children aged 6 months or older, the majority (75.4\%) were breastfed and none received exclusive breastfeeding. The amount of children who were not exclusively breastfed was 78 , with $53.8 \%$ receiving food introduction at less than 6 months of age and 5.1\% never breastfeeding. (Table 2)

Taking a parallel on knowledge and practice in breastfeeding, it was observed that $81.7 \%$ of

Table 2. Age of food introduction of children up to 2 years of age attended at the School Health Center of the Pará State University.

\begin{tabular}{|l|c|c|}
\hline \multicolumn{1}{|c|}{ Age of food introduction } & $\mathbf{N}=\mathbf{7 8}$ & $\%$ \\
\hline$<6$ months & 42 & 53.8 \\
\hline 6 months & 26 & 33.3 \\
\hline$>6$ months & 6 & 7.7 \\
\hline Never received & 4 & 5.1 \\
\hline
\end{tabular}

mothers believe that breastfeeding should be offered on demand, and the majority, $77.9 \%$, do so in practice. Regarding the interruption of the feeding, $81.7 \%$ answered that the correct thing is not to interrupt and $79.8 \%$ of them did not interrupt in practice. Dealing with the breast in which the next feeding should be started, $76.9 \%$ said that one should not start with the suckled breast last in the previous feeding and $73.1 \%$ practiced this way.

\section{(Table 3)}

As for the knowledge, 95.2\% do not believe that breast milk is "weaker" than cow's milk, and most answered that breast milk is able to protect the child from disease $(98.1 \%)$, which give only milk maternal nutrition for children up to 6 months is enough to nourish it (89.4\%), and is also sufficient to keep the child satiated (65.4\%).

Regarding complementary feeding and mothers' knowledge about the subject, $83.7 \%$ answered that the correct age for feeding is 6 months. About the most appropriate food for this introduction $71.2 \%$ believe that vegetables and fruits are correct and that, at the age of 6 months to 1 year the vegetables, fruits and beans, according to $62.5 \%$ researched. (Table 4)

Table 3. Knowledge and practice in maternal breastfeeding of children up to 2 years of age attended at the School Health Center of the Pará State University.

\begin{tabular}{|c|c|c|c|c|c|c|}
\hline \multirow{2}{*}{ Questionnaire } & \multicolumn{2}{|c|}{ Yes } & \multicolumn{2}{|c|}{ No } & \multicolumn{2}{|c|}{ Not Mentioned } \\
\hline & $n$ & $\%$ & $\mathrm{n}$ & $\%$ & $n$ & $\%$ \\
\hline Is cow milk more healthy than breast milk? & 5 & 4.8 & 99 & 95.2 & 0 & 0 \\
\hline Is breast milk capable of protecting the children from diseases? & 102 & 98.1 & 2 & 1.9 & 0 & 0 \\
\hline Is exclusive breastfeeding for the first 6 months enough to nourish the children? & 93 & 89.4 & 11 & 10.6 & 0 & 0 \\
\hline Can exclusive breastfeeding for the first 6 months keep the children satiated? & 68 & 65.4 & 36 & 34.6 & 0 & 0 \\
\hline Should you offer the breast whenever the children wants, on demand? & 85 & 81.7 & 19 & 18.3 & 0 & 0 \\
\hline Do/did you offer the breast whenever the children wants? & 81 & 77.9 & 21 & 20.2 & 2 & 1.9 \\
\hline $\begin{array}{l}\text { Should not be interrupted the breastfeeding, that is, should one breast be } \\
\text { offered until the baby releases and then offer the other? }\end{array}$ & 85 & 81.7 & 19 & 18.3 & 0 & 0 \\
\hline Do/did you interrupt the breastfeeding? & 19 & 18.3 & 83 & 79.8 & 2 & 1.9 \\
\hline $\begin{array}{l}\text { At the next feed, should one start with the breast that the baby sucked last in } \\
\text { the previous feed? }\end{array}$ & 24 & 23.1 & 80 & 76.9 & 0 & 0 \\
\hline Do/did you start with the breast the baby sucked last in the previous feed? & 26 & 25.0 & 76 & 73.1 & 2 & 1.9 \\
\hline
\end{tabular}


Table 4. Knowledge about complementary feeding of mother of children up to 2 years of age attended at the School Health Center of the Pará State University.

\begin{tabular}{|c|c|c|}
\hline $\begin{array}{l}\text { Knowledege about } \\
\text { complementary feeding }\end{array}$ & $\mathrm{N}=104$ & $\%$ \\
\hline \multicolumn{3}{|l|}{ Age of food introduction (months) } \\
\hline 6 & 87 & 83.7 \\
\hline 12 & 8 & 7.7 \\
\hline 4 & 5 & 4.8 \\
\hline When the mother think it is better & 4 & 3.8 \\
\hline \multicolumn{3}{|l|}{ First aproppriate food } \\
\hline Vegetables and fruits & 74 & 71.2 \\
\hline Porridge & 15 & 14.4 \\
\hline Teas and juices & 15 & 14.4 \\
\hline Meat & 0 & 0 \\
\hline \multicolumn{3}{|c|}{ Most adequated between 6 months to 1 year old } \\
\hline Vegetables, fruits and bean & 65 & 62.5 \\
\hline Soup and porridge & 39 & 37.5 \\
\hline Yogurt & 0 & 0 \\
\hline Teas and juice & 0 & 0 \\
\hline \multicolumn{3}{|l|}{ More adequate food presentation } \\
\hline Kneading with fork & 53 & 50.9 \\
\hline Beaten in the blender & 37 & 35.6 \\
\hline Sifted & 11 & 10.6 \\
\hline In small pieces & 3 & 2.9 \\
\hline \multicolumn{3}{|l|}{ What to offer food } \\
\hline Spoon/forks & 49 & 47.1 \\
\hline Cups & 31 & 29.8 \\
\hline Baby bottles & 21 & 20.2 \\
\hline Mini baby bottles & 3 & 2.9 \\
\hline
\end{tabular}

Concerning the most adequate presentation of the food, $50.9 \%$ of the mothers answered that it should be offered kneaded with a fork and 35.6\% answered that the mixer was the correct one. In the opinion of $47.1 \%$ of those surveyed, food should be offered with spoon / fork and $29.8 \%$ believe that it should be offered with glasses.

Regarding the practices of mothers in complementary feeding, $28.8 \%$ of the mothers offered ho- memade baby food (with vegetables, tubers, beans, meat, etc) as the first food introduced, $22.1 \%$ offered fruits and $20.1 \%$, natural juice. (Table 5)

The foods that mothers used to offer to their children up to 2 years old were natural juice, present in the response of $62.5 \%$, porridge $(44.2 \%)$ and petit-suisse cheese (33.6\%).

Table 5. First foods introduced in the feeding of children up to 2 years old attended at the School Health Center of the Pará State University.

\begin{tabular}{|l|c|c|}
\hline \multicolumn{1}{|c|}{ Food } & Rate & $\%$ \\
\hline Homemade baby food & 40 & 28.8 \\
\hline Fruits & 30 & 22.1 \\
\hline Natural juice & 21 & 20.1 \\
\hline Porridge & 14 & 13.4 \\
\hline Infant formula & 7 & 5.7 \\
\hline Water & 6 & 5.7 \\
\hline Tea & 3 & 2.8 \\
\hline Others & 4 & 2.8 \\
\hline
\end{tabular}

Source: Research protoco

\section{Discussion}

Breastfeeding and the introduction of food are essential factors for the adequate growth and development of the child, and good knowledge about the subject and the correct practice is essential.

In the present study, the majority of children under 6 months of age were exclusively breastfed and among the children aged 6 months or older, the majority were breastfed, but they already received complementary feeding. The feeding of most infants was performed before the age of six months, which is considered early according to the guidelines of the World Health Organization (WHO) and the Ministry of Health [4].

Oliveira et al. shows that the inexperience associated with the lack of information regarding breastfeeding may be related to maternal insecurity in adopting her milk as the only food for their children 
and in an attempt to find solutions for intercurrences. In the present study, it is observed that the majority of the children is the firstborn one, which could explain a lack of experience of the mothers [5]. According to the Ministry of Health in 2015, the stimulus to breastfeeding during pregnancy has a positive impact on the prevalence of breastfeeding, especially among primiparous women, with prenatal care being an excellent opportunity to motivate women to breastfeed [4].

The mothers of this study mostly attended to 6 or more prenatal consultations, which is recommended by the Ministry of Health in their Prenatal and Postpartum Manual [6]. This finding demonstrates that although most go to an enough number of prenatal consultations, the majority of them practiced the introduction of early food, indicating the importance and necessity of studies that show the quality of prenatal consultations independently of this type of orientation.

With respect to previous information on breastfeeding, it was observed that mothers have correct knowledge about the benefits of breastfeeding in agreement with what is recommended by the Ministry of Health [4]. However, as to the breast in which to begin the feeding, an error was observed in both knowledge and practice. It is recommended to start with the breast in which the baby was sucking last, since milk at the end of the feed is more caloric, causing satiety and weight gain [7]. This error was observed, although the mothers have good knowledge about other issues involving breastfeeding, demonstrating that there is still a failure in the orientation of the mothers. This may be related to a deficiency in the preparation of health professionals for important information on breastfeeding, as shown by Moimaz et al [8]. In his study, in which a large part of the community health agents felt incapable of practicing guidance of mothers. Regarding the mothers' knowledge about the benefits to the baby in the breastfeeding, $86.9 \%$ of the mothers believed that there were benefits to children, but only $48.8 \%$ breastfed.

Concerning what influences in practice, the level of education and work outside the home is expected to influence the adherence to exclusive breastfeeding, since studies such as that of Souza et al. show that the majority of mothers exclusively breastfeed their children under 6 months had completed higher education and was on maternity leave. [9] The present study differed from these results, since most of the mothers studied with good educational level, maternity leave or unemployed had begun to introduce their children's food before 6 months of age.

In relation to children who were no longer under exclusive maternal breastfeeding, the majority stopped receiving it before 6 months, starting complementary feeding early. There is some disagreement about this information in relation to the knowledge presented by mothers about infant feeding, since a large majority responded correctly when asked about at what age it is recommended to start introducing other foods than breast milk.

Regarding the maternal knowledge about complementary feeding, the results presented in this research were satisfactory. In general, they agreed with the Ministry of Health guidelines, which indicates the gradual introduction of complementary foods in the form of potatoes of vegetables, fruits, cereals, vegetables and tubers, as well as meat, fats and eggs, which would be able to meet to the nutritional needs of the child from the sixth month of life. [10]

When questioned about what to use to provide the food to a 6-month-old child, most of the mothers in this study answered "spoon or fork", followed by the "cups" option. According to recommendations of WHO and the Pan American Health Organization (PAHO), complementary foods should be offered to the child using spoon and glass, which are well accepted by young children. [11] 
According to the mothers' reminder, the first foods introduced in the feeding of children were, in order of higher frequency, homemade baby food, fruits and natural juice. Mothers were also asked to indicate in a food list those they used to offer their children. The three most marked were, in order of higher frequency, natural juice, porridge and Yogurt. In this question there is a certain disagreement of the practice regarding the answers about the knowledge. According to WHO studies, children (and later, in adulthood) tend to prefer foods the way they were presented initially. Therefore, it is recommended that the child is offered initially foods low in sugar and salt [12].

Some studies have shown that adolescent mothers are more likely to offer their children foods commonly eaten by them, such as soft drinks, crackers and snack foods, which are, in turn, unsuitable for children under 01-year-old [13]. The fact that most mothers in this study are no longer in the teenage age group may explain why such foods were not frequently cited in maternal practice.

Healthy and diverse food represents an opportunity for the child to be exposed to a wide range of foods that will form the basis for future alimentary habits. It is observed the deficiency of work on the factors that interfere in the development of infant food behavior and in the beginning of the alimentary preferences from the practices during the first years of life. It is also necessary to clarify how external influences, such as the media and health professionals, may interfere positively or not in this process.

\section{Conclusion}

The majority of mothers presented gook knowledge of the most of the issues about breastfeeding and complementary feeding. However, there still are some errors regarding breastfeeding techniques and age of weaning.

Such data highlight the need for further studies in order to investigate reasons for differences bet- ween practice and knowledge about these themes, analysing instructions given in prenatal care, errors or the absence of prenatal care.

\section{References}

1. Dar-Odeh, Najla S, Al-Beyari M, Abu-Hammad OA. The role of antifungal drugs in the management of stomatitis. Int Arab J Antimicrob Agents 2012;2:1-5. doi:10.3823/705.

2. Dar-Odeh NS, Al-Abdalla M, Al-Shayyab MH, Obeidat $H$, Obeidat L, Kar MA, et al. Prescribing Antibiotics for pediatric dental patients in Jordan; knowledge and attitudes of dentists. Int Arab J Antimicrob Agents 2013; 3:4. doi:10.3823/736.

3. Tomczyk S, Whitten T, Holzbauer SM LR. Combating antibiotic resistance: a survey on the antibiotic-prescribing habits of dentists. Gen Dent 2018; 66:61-8.

4. Bird L, Landes D, Robson T, Sturrock A LJ. Higher antibiotic prescribing propensity of dentists in deprived areas and those with greater access to care in the North East and Cumbria, UK. Br Dent J 2018; 225:517-24.

5. Greenstein, Gary, Greenstein B. Clinical Management of Acute Orofacial Infections. Compend Contin Educ Dent 2015; 36:96103.

6. Dar-Odeh N, Fadel HT, Abu-Hammad S, Abdeljawad R, AbuHammad OA. Antibiotic prescribing for Oro-facial infections in the paediatric outpatient: A review. Antibiotics 2018; 7. doi:10.3390/antibiotics7020038.

7. ipahi Calis A, Ozveri Koyuncu B, Ozturk K, Mert A BC. General approach to the treatment of odontogenic abscesses and cost analysis. J Istanb Univ Fac Dent 2015; 49:17-22.

8. Majid OW, Al-Mashhadani BA. Perioperative bromelain reduces pain and swelling and improves quality of life measures after mandibular third molar surgery: A randomized, double-blind, placebo-controlled clinical trial. J Oral Maxillofac Surg 2014. doi:10.1016/j.joms.2013.12.035.

9. Singh T, More V, Fatima U, Karpe T, Aleem MA, Prameela J. Effect of proteolytic enzyme bromelain on pain and swelling after removal of third molars. J Int Soc Prev Community Dent 2016. doi:10.4103/2231-0762.197192.

10. Ghensi P, Cucchi A, Creminelli L, Tomasi C, Zavan B, Maiorana C. Effect of Oral Administration of Bromelain on Postoperative Discomfort after Third Molar Surgery. J Craniofac Surg 2017. doi:10.1097/SCS.0000000000003154.

11. Domanski D, Zegrocka-Stendel O, Perzanowska A, Dutkiewicz M, Kowalewska M, Grabowska I, et al. Molecular mechanism for cellular response to $\beta$-escin and its therapeutic implications. PLoS One 2016. doi:10.1371/journal.pone.0164365. 
12. Tiffany $N$, Boon $H$, Ulbricht $C$, Basch E, Bent S, Barrette EP, et al. Horse chestnut:a multidisciplinary clinical review. J Herb Pharmacother 2002.

13. Frick RW. Three treatments for chronic venous insufficiency: Escin, hydroxyethylrutoside, and Daflon. Angiology 2000. doi:10.1177/000331970005100303.

14. Gupta SC, Tyagi AK, Deshmukh-Taskar P, Hinojosa M, Prasad S, Aggarwal BB. Downregulation of tumor necrosis factor and other proinflammatory biomarkers by polyphenols. Arch Biochem Biophys 2014. doi:10.1016/j.abb.2014.06.006.

15. Ottillinger B, Greeske K. Rational therapy of chronic venous insufficiency - Chances and limits of the therapeutic use of horse-chestnut seeds extract. BMC Cardiovasc Disord 2001. doi:10.1186/1471-2261-1-5.

16. Wilkinson JA, Brown AMG. Horse chestnut - Aesculus hippocastanum: Potential applications in cosmetic skincare products. Int J Cosmet Sci 1999. doi:10.1046/j.14672494.1999.234192.x

17. Dudek-Makuch M, Studzińska-Sroka E. Horse chestnut - efficacy and safety in chronic venous insufficiency: an overview. Rev Bras Farmacogn 2015. doi:10.1016/j.bjp.2015.05.009

18. Bayer G. Martindale: The Complete Drug Reference. 38th ed. Aust Prescr 2015. doi:10.18773/austprescr.2015.023.

19. Taussig SJ. The mechanism of the physiological action of bromelain. Med Hypotheses 1980. doi:10.1016/03069877(80)90038-9.

20. Orsini RA. Bromelain. Plast Reconstr Surg 2006. doi:10.1097/01. prs.0000242503.50548.ee.

21. Ordesi $P$, Pisoni $L$, Nannei $P$, Macchi M, Borloni R, Siervo S. Therapeutic efficacy of bromelain in impacted third molar surgery: A randomized controlled clinical study. Quintessence Int (Berl) 2014. doi:10.3290/j.qi.a32237.

22. Bormann KH, Weber K, Kloppenburg $H$, Koch A, Meiser $P$, Gellrich NC. Perioperative Bromelain Therapy after Wisdom Teeth Extraction - A Randomized, Placebo-Controlled, DoubleBlinded, Three-Armed, Cross-Over Dose-Finding Study. Phyther Res 2016. doi:10.1002/ptr.5707.
23. Zatuchni GI, Colombi DJ. Bromelains therapy for the prevention of episiotomy pain. Obstet Gynecol 1967.

24. de $R$, de Sousa Lima FCM, do BC. Is bromelain an effective drug for the control of pain and inflammation associated with impacted third molar surgery? Systematic review and meta-analysis. Int J Oral Maxillofac Surg 2018. doi:10.1016/j. ijom.2018.07.028

25. Maurer HR. Bromelain: Biochemistry, pharmacology and medical use. Cell Mol Life Sci 2001. doi:10.1007/PL00000936.

26. Reddy KK, Grossman L, Rogers GS. Common complementary and alternative therapies with potential use in dermatologic surgery: Risks and benefits. J Am Acad Dermatol 2013. doi:10.1016/j.jaad.2011.06.030.

27. Morse DR. Oral Pathways of Infection. Int Endod J 1972. doi:10.1111/j.1365-2591.1972.tb00064.x

28. Obayashi N, Ariji Y, Goto M, Izumi M, Naitoh M, Kurita K, et al. Spread of odontogenic infection originating in the maxillary teeth: Computerized tomographic assessment. Oral Surgery, Oral Med Oral Pathol Oral Radiol Endodontology 2004. doi:10.1016/j.tripleo.2004.05.014.
Publish in International Archives of Medicine

International Archives of Medicine is an open access journal publishing articles encompassing all aspects of medical science and clinical practice. IAM is considered a megajournal with independent sections on all areas of medicine. IAM is a really international journal with authors and board members from all around the world. The journal is widely indexed and classified Q2 in category Medicine. 